\title{
Introducing Engineering Technology Students to Ethical Engineering Decision Process
}

\section{Dr. Carmen Cioc, The University of Toledo}

Dr. Carmen Cioc is an associate professor in Mechanical Engineering Technology at the University of Toledo. She teaches courses in mechanical design and thermal fluids, including statics and strengths of materials, mechanical design, thermodynamics, and fluid mechanics. Her research interests are in engineering education, applied thermal sciences, and tribology. Dr. Cioc earned her first master's degree (1992) in Aerospace Engineering at Polytechnic University of Bucharest, her second Master of Science (2012) in Physics - Professional in Photovoltaics at the University of Toledo, and her Doctor of Philosophy (2004) in Engineering at the University of Toledo.

\section{Dr. Sorin Cioc, University of Toledo}

Dr. Sorin Cioc is a clinical associate professor and undergraduate program director in the Department of Mechanical, Industrial, and Manufacturing Engineering (MIME).

Prof. Richard Arthur Springman, The University of Toledo 


\title{
Introducing ET Students to Ethical Engineering Decision Process
}

\begin{abstract}
This paper describes the authors' efforts to introduce ethics in various Engineering Technology courses, from the freshman-level Orientation course to the senior-level Design Capstone course. Students at all levels are introduced to the code of ethics for engineers and to the nine steps of the ethical engineering decision. Three main teaching methods are used: case studies such as those presented by NSPE, invited external speakers, and peer review in engineering. Debate groups are used to discuss each of the case studies, while student peer review is used in multiple courses. A particular attention is given to students' responsibilities and cheating in classrooms. The former ABET criterion 3, student outcomes (i) "an understanding of and a commitment to address professional and ethical responsibilities including a respect for diversity" as well as the new 2019-2020 ABET criterion 5, curriculum, discipline specific content (E) "Include topics related to professional responsibilities, ethical responsibilities, respect for diversity, and quality and continuous improvement" is addressed in these educational experiences ${ }^{(1)}$.
\end{abstract}

\section{Introduction}

Engineering Technology (ET) is one of the six academic departments in the College of Engineering (COE) at the University of Toledo and it is the largest in terms of number of undergraduate students enrolled, currently around 1000 students. The ET Department offers ABET-accredited Bachelor of Science degrees in five areas of study, namely Computer Science and Engineering Technology (CSET), Construction Engineering Technology (CET), Electrical Engineering Technology (EET), Information Technology (IT), and Mechanical Engineering Technology $(\mathrm{MET})^{(2)}$. The IT program is ABET accredited by the CAC division, rather than the ETAC division.

It should be noted that Ethics and Professional Practice is a subject area included in the Fundamentals of Engineering (FE) examination that is required for registration as a professional engineer. In reviewing the subject matter guidelines for the seven discipline areas in which the exam is offered, ethics accounts for from two to eight questions of the total 110 questions on the exam. The specific areas included in Ethics and Professional Practice can be broken down into the following topics ${ }^{(3)}$ :

- Code of ethics and licensure

- Agreements, contracts and contract law

- Ethical and legal considerations

- Professional, ethical, and legal responsibility

- Sustainability and sustainable design

- Professional skills

- Professional liability

- Public protection and regulatory issues

- NCEES Model Law and Model Rules

○ Intellectual property

- Public health, safety, and welfare 
While these topics represent more than enough material upon which to structure a course, it is often difficult to bring that all together in a single course that can serve each of the five majors which are offered through Engineering Technology at the University of Toledo.

All but the Information Technology graduates are qualified to sit for the FE exam. Some of the programs include courses that address a specific topic in the above list. For instance, the Construction Engineering Technology curriculum includes the courses CET 1150 Construction Materials and Codes and CET 3160 Contracts and Specifications. All of the programs have electives in technical/professional development areas. Three of the options which can be used to fulfill this requirement are BUAD 3470 Legal and Ethical Environment of Business, BLAW 3570 Laws of Structuring and Operating a Business, and MET 4600 Engineering Safety. Thus, there are avenues within each of the degree programs to expose the students to specific elements within the broader topic of ethics. Consequently, a more practical approach for the department has been to include ethics subject matter in a variety of courses throughout the curriculum. This permits the introduction of a wider variety of topics at appropriate times in the program and adds the benefit of reinforcement by virtue of repetition.

In this context, repetition does not merely mean repeating a singular topic, but presenting it in differing formats to accommodate the needs of the host course. For instance, the subject of licensure (professional registration for engineers) is included in ENGT 1000 Orientation to Engineering Technology, ENGT 2000 Professional Development, and ENGT 4050 Senior Technology Capstone. Other of the specific topics are included at appropriate points in the curriculum, such as presenting material related to public protection and regulatory (code) issues in applications-oriented courses, such as CSET 3100 Advanced Website Design, CSET 4850 Computer and Network Security, MET 3200 Mechanical Design I, MET 4200 Mechanical Design II, ENGT 3050 Fundamentals of Electricity, EET 2410 Programmable Controllers.

With respect to academic life, a major ethical concern faced by instructors in the classrooms is cheating. In our College of Engineering, when an instructor discovers a breach of the university's policy on academic honesty by a student, they inform the Dean of Undergraduate Studies, who then notifies the student that they have been accused of cheating and also documents the incident. The student then has a definite period of time in which to appeal the decision.

\section{Academic Misconduct}

Over the past four academic years, from fall 2015 to fall 2019, out of a total of 4000 engineering students there were 296 academic misconduct incidents, of which 130 were committed by students enrolled in engineering technology programs, with a peak during the academic year 2016-2017, as shown in Figure 1. This peak can be explained in part by an added commitment of the faculty to eliminate cheating as much as possible, especially after some of the senior student exit interviews reflected the observation that there were still faculty who turn a blind eye on cheating. At the time this article was written at the end of fall 2019 semester, there were 12 incidents of academic misconduct in College of Engineering, with three of them committed by ET students.

Examples of academic misconduct include: copying and submitting CAD drawings, homework, portions of exams, or quizzes identical to the work of other students, using cell phones during examinations, submitting computer codes identical to that of another student(s) or copying codes from the internet, submitting old versions of laboratory reports, etc. 


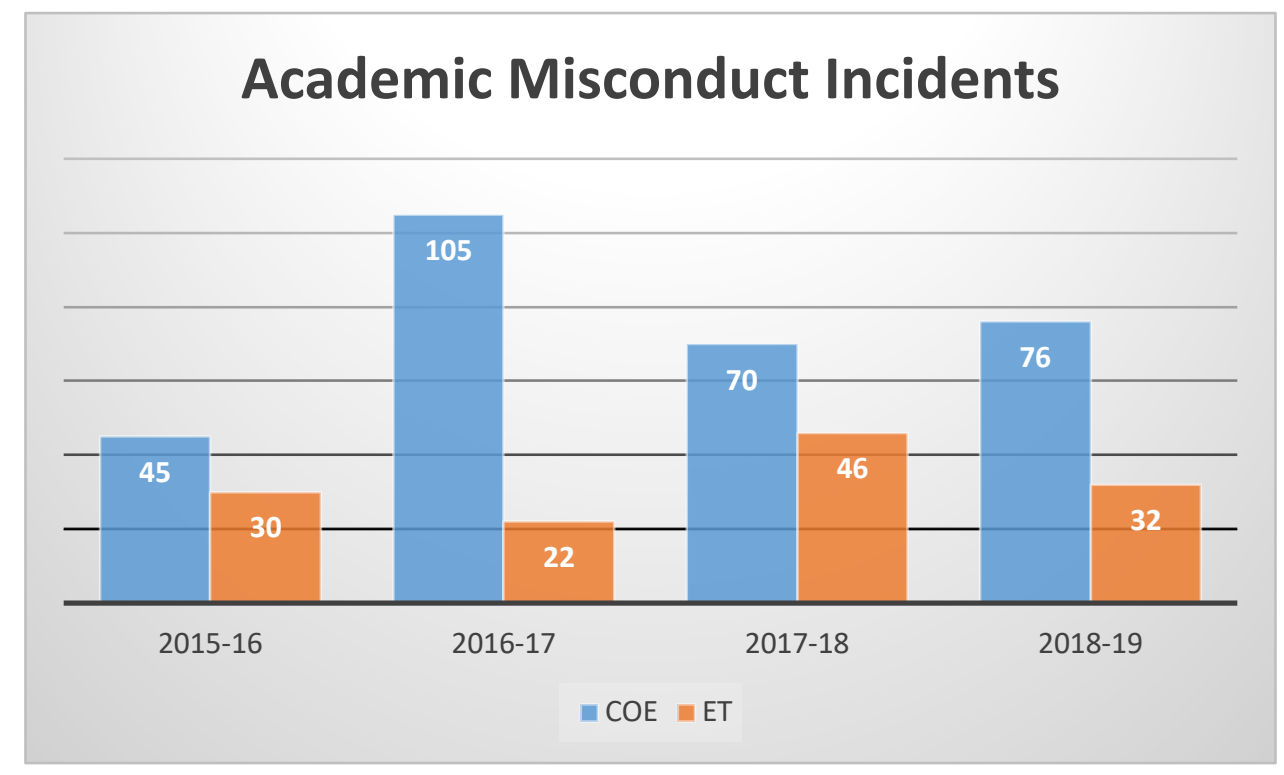

Figure 1: Academic Dishonesty Occurrence per Academic Year: fall 2015 - fall 2019

The number of reported incidents of academic misconduct committed by students in the ET programs during the period from fall 2015 through fall 2019, with the exception of IT, are shown in Figure 2. The IT program is a joint offering between the College of Engineering and the College of Business and Innovation. Thus, the decision was made to survey only those programs contained entirely within the College of Engineering.

All the ET programs except IT, informed academic misconducts during the fall 2015 - fall 2019 period, as detailed in Figure 2.

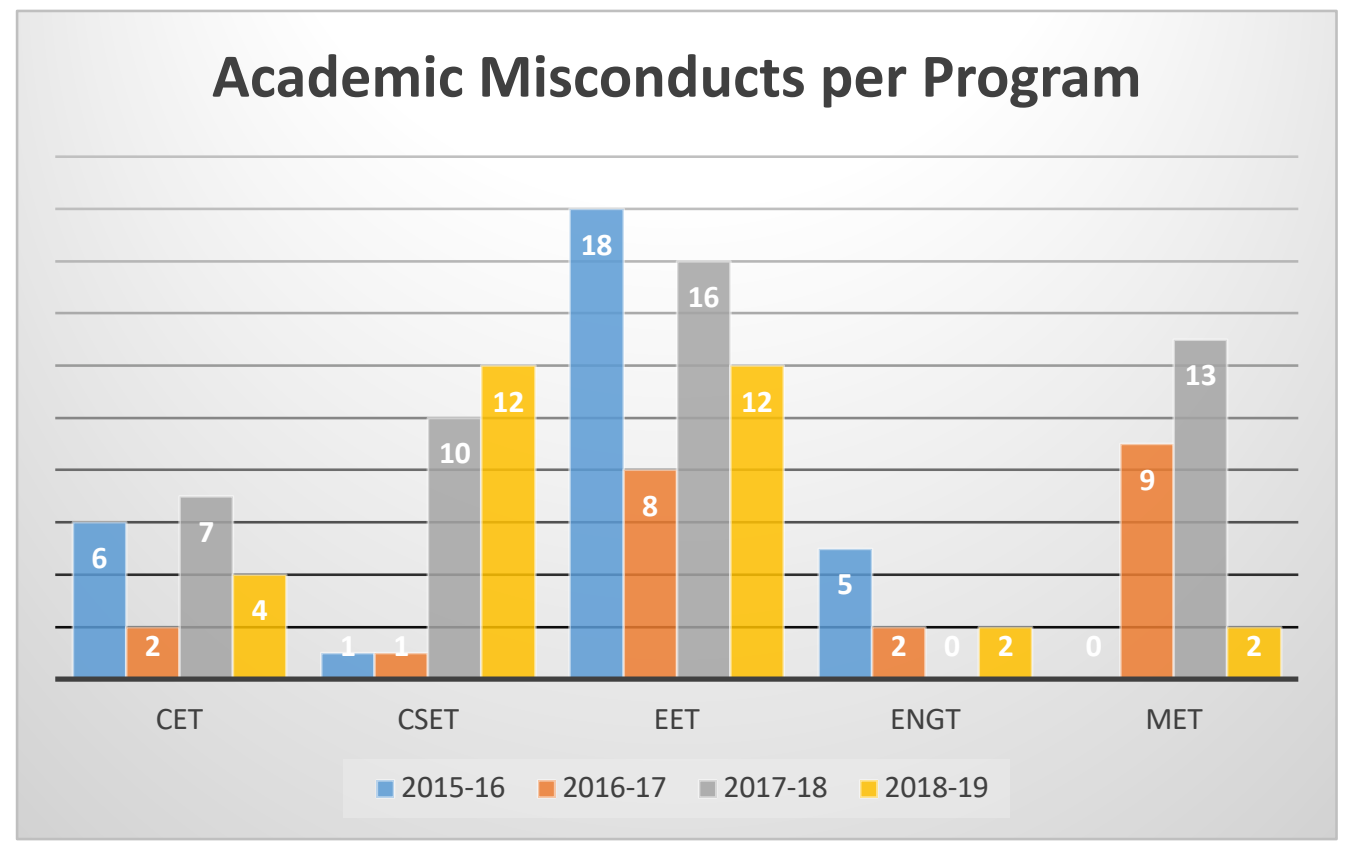

Figure 2: Academic Dishonesty Occurrence per Program of Study: fall 2015 - fall 2019 


\section{Engineering Ethics Implementations}

\section{ENGT 1000 - Introduction to Engineering Technology}

When looking at the aggregate data presented above, one might conclude that there is a strong need to add more ethical discussions in our classrooms, to repeatedly emphasize the student code of conduct and real-life ethical cases. One course considered as a good candidate for introducing such experiences is ENGT 1000 - Introduction to Engineering Technology. This course is a onecredit-hour general orientation course offered to all freshmen enrolled in our ET Department and offers an overview of careers in engineering technology, information about our programs, and skills required for success in technological fields. Additionally, the course offers an introduction to academic success strategies within a community of university learners by identifying the key strategies needed to support the transition from high school to the university, introducing the students to the campus resources, self-responsibility, academic policies and procedures, study strategies and other topics foundational to campus life.

In addition to the above-mentioned topics, a new topic of discussion, Ethics in Engineering, was introduced in fall 2018 over two 80-minute lectures. The first lecture, entitled Code of Ethics, introduced the students to the University of Toledo Academic Dishonesty Policy, the ASME Code of Ethics of Engineers ${ }^{(4)}$, and the NSPE Code of Ethics for Engineers ${ }^{(5)}$. At the end of the class, the students were asked to sign a "pledge to follow the UT's code of conduct and as an engineer, the code of ethics of engineers".

During the same lecture, the students were presented with a case study, the well-known Volkswagen Emission Scandal. The students were separated into groups of four, asked to discuss the case within their groups, and afterwards participate in a classroom debate. In the end, they were asked to identify whose fault it was, by selecting one of the four possible answers: a) VW engineers, b) VW Executives, c) VW CEO, and d) all of the above. Seventy-six students participated in this exercise, and $87 \%$ of them agreed that answer d) was the correct answer, as show in Figure 3.

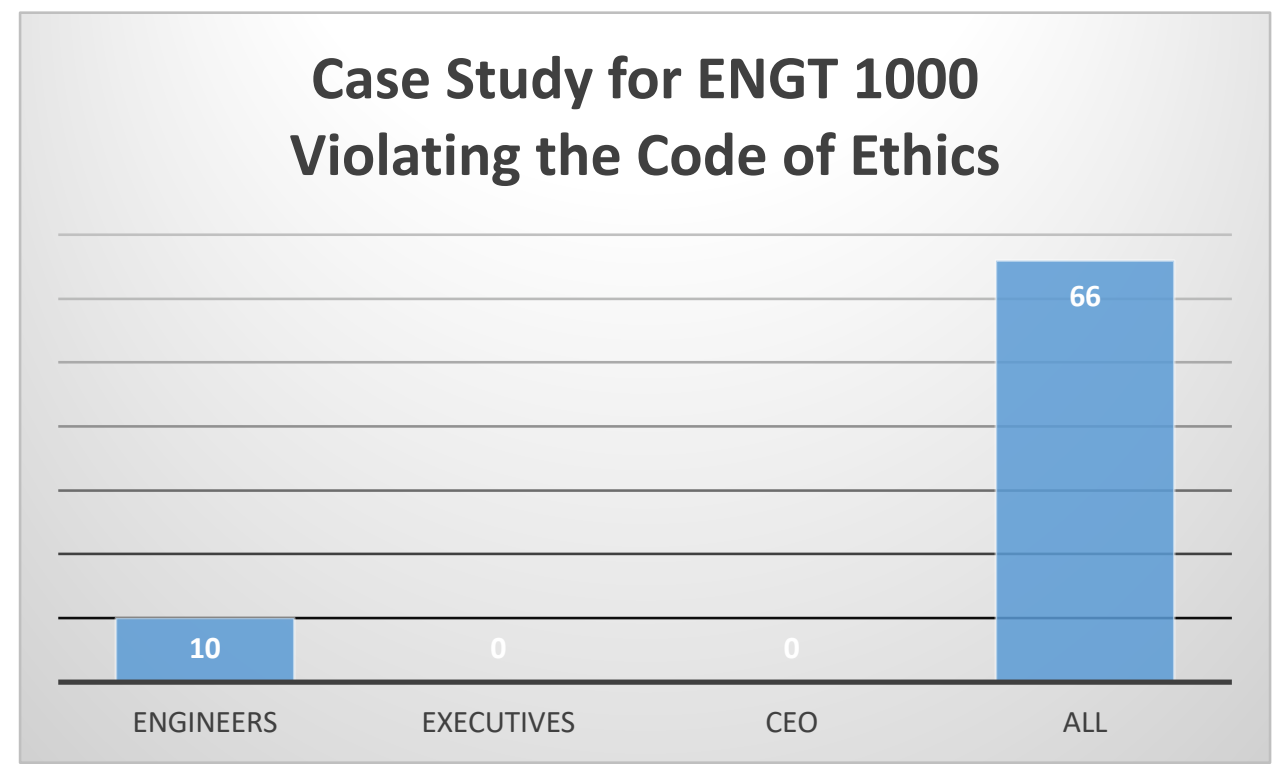

Figure 3: Case Study - Violating the Code of Ethics 
During the second lecture, entitled Ethics, the class was visited by one of our ET faculty, Mr. Gary Daugherty, Associate Lecturer in the CET program, and instructor for the MET 4600 Engineering Safety course. His talk covered the difference between ethics and morals, most common unethical behaviors in industry, examples of unethical behavior among individuals, among businesses, and unethical behavior by professionals. Five case studies were presented and debated. The students clearly enjoyed the presentation by our guest speaker in which they were asked to give an example of an unethical behavior they faced either in school or in their place of work. Sixty-six students, representing $77.2 \%$ of the class, participated in this exercise. Their responses covered a wide variety of ethical situations, ranging from cheating in school (starting with elementary school), to cheating in sports, and stealing in the workplace, as presented in Figure 4. As shown in Figure 4, at least $42 \%$ of the students were faced with school cheating in their academic life. It should be noted that about $31 \%$ of the class described a moral dilemma rather than an ethical situation.

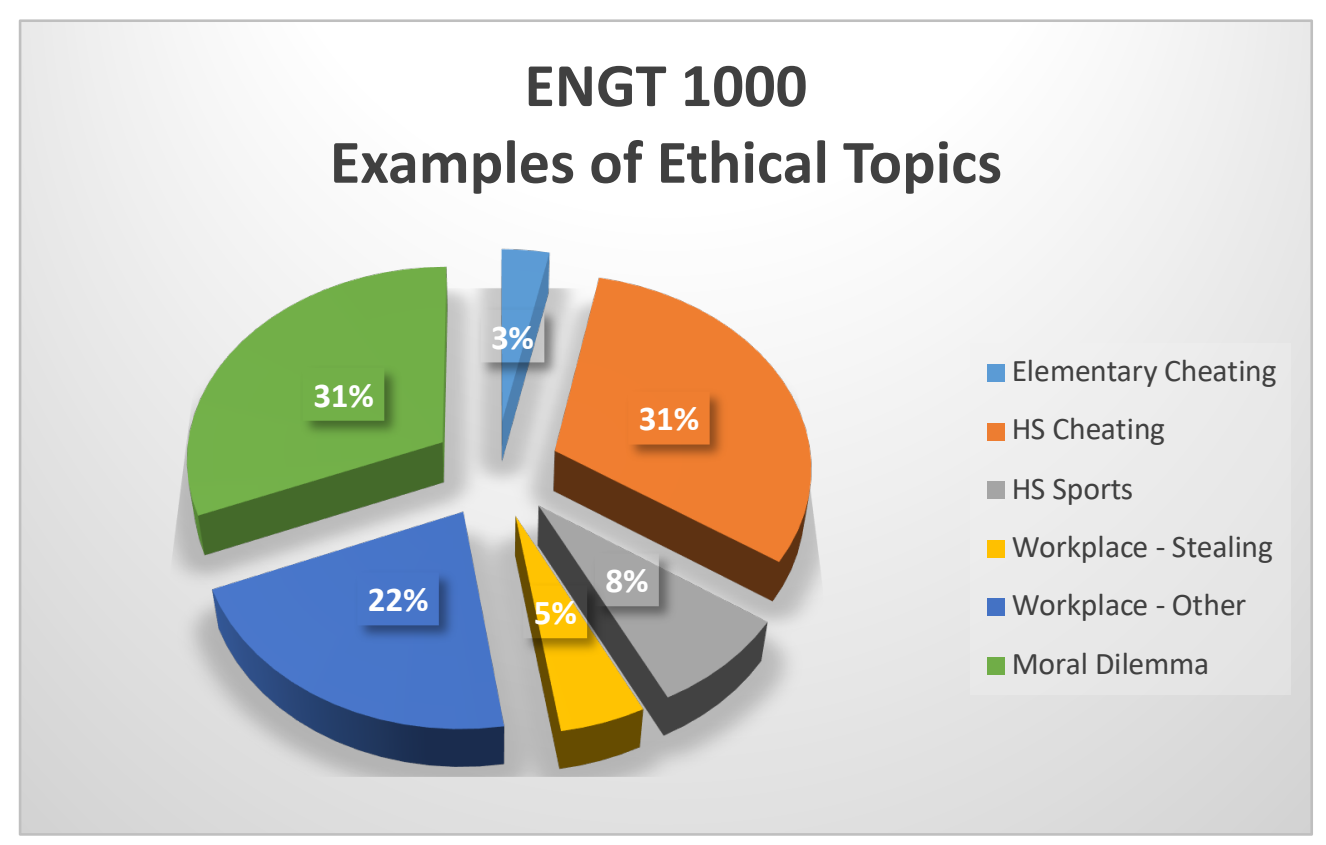

Figure 4: Examples of Ethical Topics Provided by Students Enrolled in ENGT 1000

The data gathered from this new classroom experience was used to satisfy the ABET criterion 3 , student outcomes (i) for the ENGT 1000 course and this exercise will continue to be used to satisfy the new ABET criterion 5, curriculum content E.

\section{MET 3100 - Applied Thermodynamics}

A similar educational experience was introduced in fall 2018 in the MET 3100 - Applied Thermodynamics course. Before discussing the power cycles, including the Diesel cycle, the students were introduced to the aforementioned Volkswagen Emission Scandal case study. The students were briefed on the case study, then permitted to discuss the VW case in small groups, answer a questionnaire similar to the one given in the ENGT 1000 course, and finally debate their answers. As a reminder, the four possible answers were a) VW engineers, b) VW Executives, c) VW CEO, and d) all of the above. When the papers were collected and the answers summarized, it was surprising to see that over $20 \%$ of students chose combinations of answers, as described in Figure 5. 
It was interesting to see that only $64 \%$ of the students enrolled in this course, with the majority at the junior level, believed that the correct answer was d) "all of the above", compared with $87 \%$ of the freshman class. Also, it was interesting to see that the junior students came up with their own category of people breaching the code of ethics, such as "Engineers \& CEO" and "Executives \& CEO".

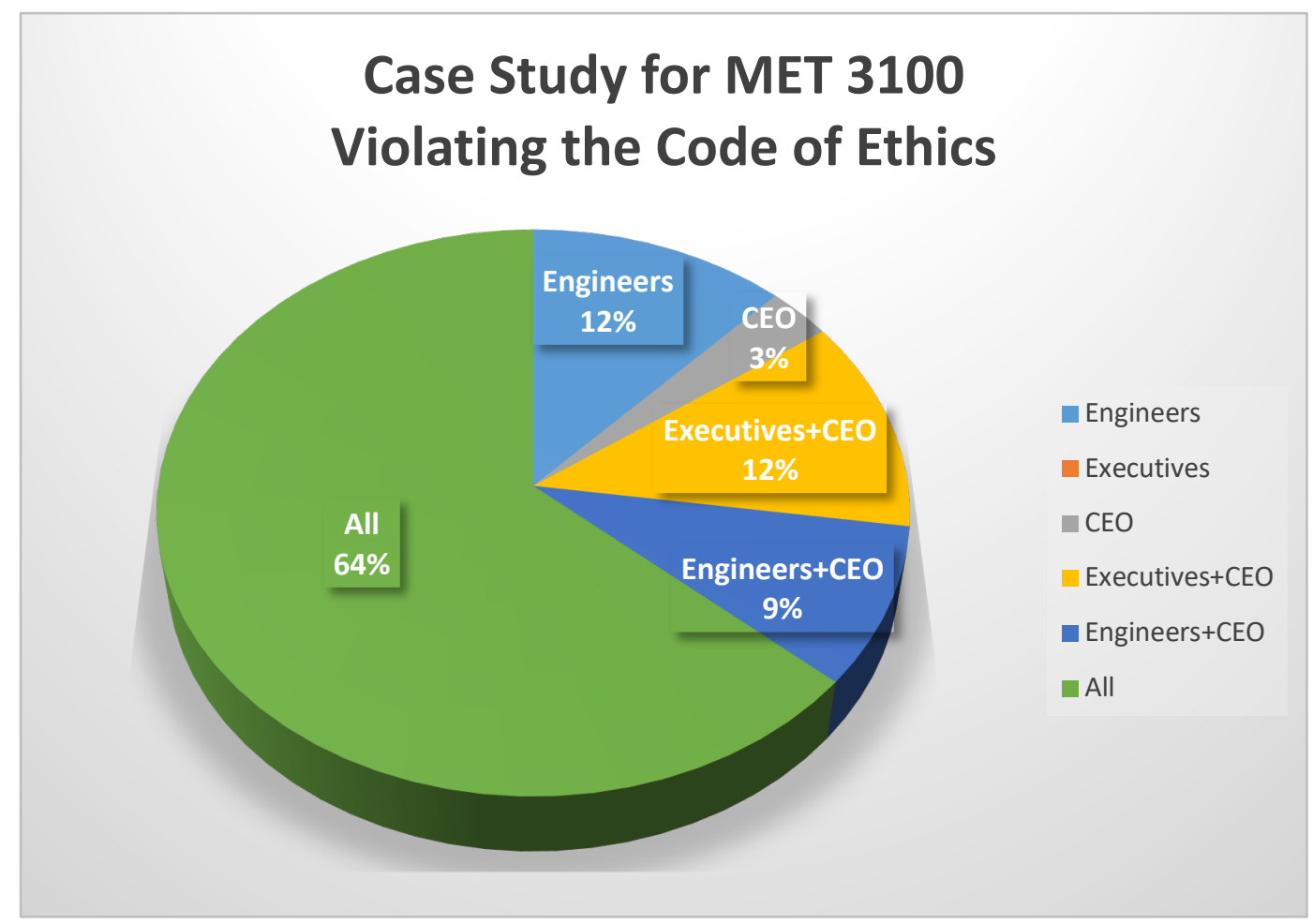

Figure 5: Case Study - Violating the Code of Ethics

During the same lecture, the students were asked to anonymously answer Yes/No to the following question "Are you interested in discussing ethical scenarios in the Thermodynamics course?", and to explain their answer. Twenty-one students out of the total of the 34 currently enrolled in MET 3100 answered. One student was undecided, and he circled both Yes and No. His remarks were: "I don't really care, but I do see the importance". Three students circled the No answer. Their comments were:

- "By year 3 or 4 for most of us, we have already dealt with most critical issues"

○ "This is thermodynamics, talk about ethics in professional development; that class is a waste of time"

○ "I just didn't like to; no reason"

Seventeen students, representing $81 \%$ of responders, liked the idea of having further discussions about ethical scenarios in the thermodynamics class; a few of their comments were:

○ "I find them to be helpful. They will also assist me in my career"

○ "Learning about something is always good"

o "Ethics are important" 
- "I believe it is important to discuss ethical issues involving real life scenarios";

○ "It can only help to further discuss ethical scenarios"

- "In real work, one of the best ways to learn is real world applications"

- "I see too many students being okay with many different forms of cheating"

- "It is inevitably a part of our lives after school. Why not learn about it?"

○ "It helps to understand situations people have been through to have an idea of the steps that need to take place if you find yourself with something similar"

- "Approaching graduation, it is a great time to discuss ethics before obtaining the firsttime job";

In addition, similar to the homework assigned in ENGT 1000, the students from MET 3100 were asked to provide, anonymously, an example of an ethical problem they encountered either as students or in their workplace. A similar classification as that from Figure 4 was used for this course, and the data is presented in Figure 6.

\section{MET 3100 Examples of Ethical Topics}

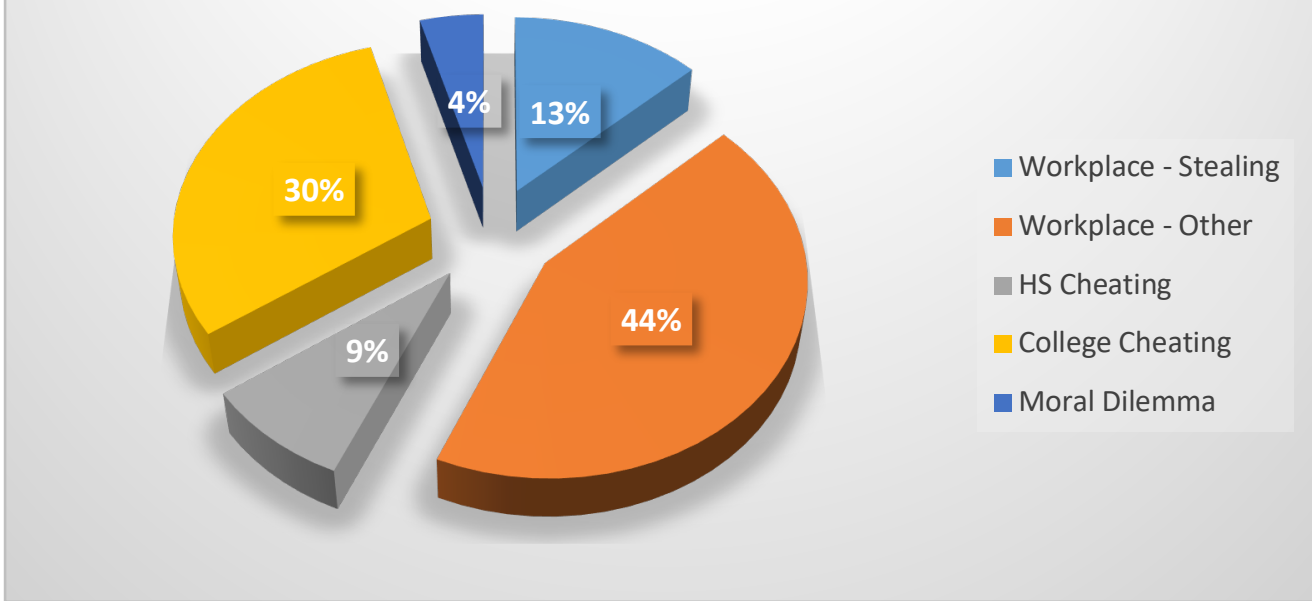

Figure 6: Examples of Ethical Topics Provided by Students Enrolled in MET 3100

It is important to note that only $4 \%$ of the examples cover a moral dilemma compared with $31 \%$ of those provided by the freshmen, indicating perhaps that in the space of a couple of years, the students have become more aware of the differences between ethics and morals.

The data collected from this exercise was used at that time to evaluate the ABET criterion 3, students outcomes (i) and it will be used in 2019-2020 cycle to satisfy the new ABET requirements as previously mentioned.

\section{ENGT 4050 Senior Technology Capstone}

As mentioned by one student respondee, "Approaching graduation it is a great time to discuss ethics before obtaining the first-time job". We came to the same conclusion and, consequently, the subject of intellectual property is discussed in ENGT 4050 Senior Technology Capstone. In this course, the students work in teams to solve an open-ended design problem which is then 
presented at the Undergraduate Research and Senior Design Engineering Project Exposition on the last day of class of the semester. As the students research and form a solution to their design problems, the issue of patents often arises; thus, this is an ideal time to present material on intellectual property. This is accomplished by inviting a guest speaker from the Office of Technology Transfer, who addresses the issues of copyrights, trademarks, trade secrets, and patents. The presentation includes a discussion of the intangible property rights protected by law, the infringement of those rights, and a comparison between those rights in the USA versus those in other countries. The latter issue reflects the global nature of the industries in which today's graduates find themselves upon joining the professional workforce.

\section{Conclusion}

Case studies have proven to be an excellent means of engaging the students in a discussion of professional ethics. These discussions seem particularly effective when the students are formed into groups or teams to research, discuss and present their findings. An excellent source of ethics material is available through the National Society of Professional Engineers (NSPE) ${ }^{(4)}$. Their monthly magazine, $\boldsymbol{P E}$, presents not only articles related to a variety of legal and ethical issues, but also presents a case study.

A case study includes a description of the situation, poses an ethical question and then discusses the matter with references to the NSPE Code of Ethics. One advantage in using these case studies as a classroom activity is that the NSPE Code of Ethics, which is a concise and directed document, can be used as the sole source of information by which to judge the individual case. A library of such case studies is available to NSPE members through the NSPE website ${ }^{(5)}$.

Case studies can be used as the basis for several classroom activities. One is to use them to pose ethical questions that a team of students can address and then present. This can be used as an individual assignment as well, but experience has shown that the students benefit from the discussion within the team to reach a conclusion. Another option is to pose the question in the form of a debate and have the results presented to the class by a team for each of the opposing arguments. Another option that has been used is to present the opposing arguments in the form of a courtroom trial case. This works particularly well with questions of liability.

As a unique variation on the subject of case studies, it is worth noting that NSPE in the spring of each year sponsors the Milton F. Lunch Engineering Ethics Essay Contest. The competition, which is open to all NSPE individual members and NSPE chapters, including student chapters, is centered on the presentation and discussion of an ethical situation with a conclusion supported by references to the NSPE Code of Ethics. The local University of Toledo student chapter of NSPE (UTSPE) has in the past participated in this contest.

The College of Engineering at the University of Toledo has established the tradition of inducting each semester's graduates into the Order of the Engineer in a ceremony prior to commencement. The goal of the Order is to foster a sense of pride and responsibility in the engineering profession. Each of the inductees is presented with a stainless-steel ring which is both a visible symbol to the public identifying the wearer as an engineer as well as serving as a personal reminder to the engineer of his/her professional responsibilities to the public. The Order of the Engineer ceremony is supported by The College of Engineering with assistance from the Engineering Alumni of the University of Toledo (EAUT) and the local chapter of the Society of Professional Engineers (TSPE). 
The subject of ethics is a broad topic that is an inherent element of the conduct and work product of engineers. It is specifically cited as one of the outcomes required by ABET criteria as well as a foundational principle of engineering professional societies and the engineering profession itself. Thus, we feel that it is important to include this topic in our curricula, not as a single topic but as a thread that is woven through the educational experience that we provide to our students. We have attempted to share some of those techniques which we have found successful in acquainting our students with their personal and professional obligations and hope that this will help to stimulate further discussion on the subject.

\section{References}

(1) https://www.abet.org/accreditation/accreditation-criteria/criteria-for-accreditingengineering-technology-programs-2019-2020/

(2) https://www.utoledo.edu/engineering/engineering-technology/

(3) National Council of Examiners for Engineering and Surveying, https://ncees.org/

(4) American Society of Mechanical Engineers, Ethics in Engineering https://www.asme.org/about-asme/advocacy-government-relations/ethics-in-engineering

(5) National Society of Professional Engineers, https://www.nspe.org/

(6) National Society of Professional Engineers, https://www.nspe.org/resources/ethics/ethicsresources/you-be-the-judge 